\title{
Obesity in Relation to Ovarian Response in IVF Treatment
}

\author{
Howaida Hashim1, Mahmoud Gehad', Badawi Khalid2, Fahad Al Salman', Samar Hassan1, \\ Afaf Felemban1, Haya Al Fozan1, M. Al Bugnah1
}

${ }^{1}$ IVF/Reproductive Endocrinology Unit, Obstetrics \& Gynecology Department, King Abdul Aziz Medical City, Riyadh, Saudi Arabia

${ }^{2}$ IVF Unit, OB/GYN Department, Dr. Erfan \& Bagedo General Hospital, Jeddah, Saudi Arabia

Email: Hhashimh@aol.com, Khalid.elsawahli@gmail.com

How to cite this paper: Hashim, H., Gehad, M., Khalid, B., Al Salman, F., Hassan, S., Felemban, A., Al Fozan, H. and Al Bugnah, M. (2018) Obesity in Relation to Ovarian Response in IVF Treatment. Advances in Reproductive Sciences, 6, 50-57. https://doi.org/10.4236/arsci.2018.62005

Received: April 7, 2018

Accepted: May 21, 2018

Published: May 24, 2018

Copyright $\odot 2018$ by authors and Scientific Research Publishing Inc. This work is licensed under the Creative Commons Attribution International License (CC BY 4.0).

http://creativecommons.org/licenses/by/4.0/

\begin{abstract}
Introduction: The effect of Body Mass Index (BMI), which reflects the woman's obesity, in IVF treatment cycle, remains unclear. In 1997, the World Health Organization (WHO) provided authoritative refinements to the overweight terminology and BMI cutoffs [1]. Objective: To verify the relationship between BMI and ovarian response in IVF treatment cycle. Design: Retrospective study. Materials \& Methods: The study includes 2625 IVF treatment cycles performed in our IVF center in the period of 4 years. Patients were divided into five groups using the WHO criteria according to their BMI [2]. Cancellation rate, mean last E2 before hCG administration, mean endometrial thickness, mean duration of stimulation, number of eggs retrieved, fertilization rate, pregnancy and abortion rates were analyzed. The unpaired t-test was used in statistical analysis. Results: There was statistically significant less mean oestradiol level prior to hCG, less endometrial thickness and less number of simulation days as BMI gets higher. In contrast, there was a positive relationship between cancellation rate and higher BMI except with BMI $>39$ which was not, possibly due to lower number of patients available. But if we look at the cause of cancellation, it was $100 \%$ due to insufficient number of follicles obtained for this group (BMI >39). Also, days of stimulation are significantly lower for the same group of patients in comparison with the other groups. Retrieval, fertilization and pregnancy rates were not significant between all groups. Abortion rate gets significantly higher as BMI increased. Conclusion: Overweight affects ovulation, if we consider the cause of cancellation being insufficient number of follicles reflects the poor response. The fertilization and pregnancy rate were not affected once oocytes retrieved. The reduction of weight is an important
\end{abstract}


part of infertility treatment in obese women with regards to the ovarian response and abortion rate in IVF cycle.

\section{Keywords}

Body Mass Index, IVF, Pregnancy Rate

\section{Introduction}

There are numerous studies and publications that demonstrate the sub-optimal reproductive ability of obese women, the consequences of the obesity on in vitro fertilization/Intracytoplasmic Sperm Injection (IVF/ICSI) have been in the focus of contemporary infertility research. Overweight and obese women experience a lower probability for pregnancy after IVF [3]. Body Mass Index (BMI) is inversely related to intrafollicular human chorionic gonadotropin (hCG) concentrations, embryo quality and IVF outcome [4]. Despite the increasing prevalence of obesity, obese women make up a lesser proportion of women who obtain fertility-related services and the large majority of infertile women are still in the non-obese BMI range [5] [6] [7]. Against this background, it would be important to evaluate the influence of BMI on IVF outcome among the non-obese women [8] [9] [10].

\section{Method}

We investigated the influence of BMI on outcome of fresh IVF cycles in obese women. This investigation was made in a retrospective observation in the period of 4 years. Medical records in our department were kept in an electronic format.

A standardized infertility evaluation was performed on all study participants. In order to disable the effects of male infertility on IVF outcome, we included only women whose partners had normal semen analysis.

Study participants' included cycles (2625) were divided into five groups using the WHO criteria according to their BMI: group 1 (BMI < 25), group 2 (BMI 25 - 30), group 3 (BMI 31 - 34), group 4 (BMI 35 - 39) and group 5 (BMI > 39) (Table 1). Calculation of BMI was performed from anthropometric measurements of patients obtained in our department. Patients were measured on a digital scale that shows body weight in kilograms by the reliability of $\pm 100 \mathrm{~g}$. Measurement of body height was done in standing position (without shoes) with the shoulders in relaxing position and was measured in centimeters to the nearest $0.5 \mathrm{~cm}$ tick marks.

Several characteristics of study participants were analyzed to eliminate possible confounding factors influencing the outcome of IVF such as age, anti-mullerian hormone $(\mathrm{AMH})$, basal serum concentrations of estradiol $\left(\mathrm{E}_{2}\right)$, follicle-stimulation hormone (FSH), duration of infertility, type of infertility (primary, secondary) and type of stimulating protocol [11] [12] [13] [14] [15]. 
Table 1. Distribution of patients according to the BMI category.

\begin{tabular}{cccccc}
\hline Group & 1 & 2 & 3 & 4 & 5 \\
\hline No. of Cases & 482 & 1112 & 639 & 345 & 47 \\
BMI & $<25$ & $25-30$ & $31-34$ & $35-39$ & $>39$ \\
\hline
\end{tabular}

At the level of stimulation protocol, we evaluated the cancellation rate and the reason of cancellation whether, due to excessive number of follicles or not sufficient number of follicles.

\section{Results}

The number of cycles evaluated was 2625 IVF/ICSI cycles. Statistical significant difference was found at less mean estradiol level prior to hCG, less endometrial thickness and less number of simulation days as BMI gets higher.

In contrast, there was a positive relationship between cancellation rate and higher BMI except with BMI > 39 which was not, possibly due to lower number of patients available.

But if we look at the cause of cancellation it was $100 \%$ due to insufficient number of follicles obtained for this group (BMI > 39). Also, days of stimulation are significantly lower for the same group of patients in comparison with the other groups. Retrieval, fertilization and pregnancy rates were not significant between all groups. Abortion rate gets significantly higher as BMI increased.

\section{Cancellation rate due to insufficient number of follicles}

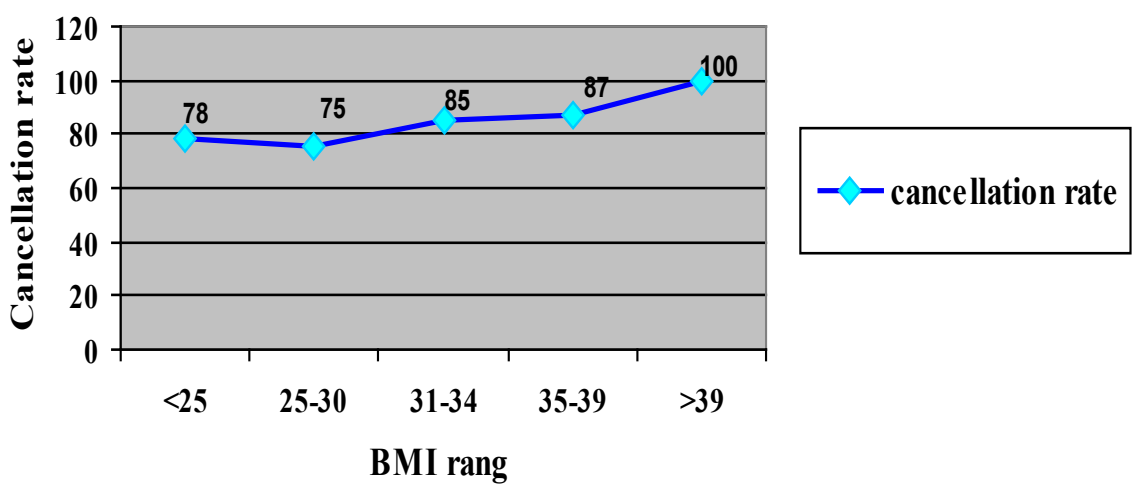

\section{Discussion}

According to the Centers for Disease Control and prevention (CDC), the Body Mass Index (BMI) is a person's weight in kilograms divided by the square of height in meters. A high BMI can be an indicator of high body fatness. BMI can be used to screen for weight categories that may lead to health problems but it is not diagnostic of the body fatness or health of an individual.

The present study investigated the BMI with relation to the cancellation of the IVF/ICSI cycle, no oocyte donation was included in this group [16] [17] [18]. There was no statistical significant effect found on the fertilization and preg- 
nancy rate between five groups [19]-[28].

Studies of IVF published in 2011 by Luke et al. and in 2008 by Sneed ML et al. [29] and [30], evaluated the age-related effect and obesity on IVF. This study analyzed the number of 45,000 embryo transfers and concluded that higher obesity levels (BMI values) resulted in a significant increase in the ability to achieve clinical pregnancy via the use of autologous oocytes but resulted in no differences in the use of donor oocytes. Besides, it reported that the adverse effects of obesity were more evident in the group aged under 35 years old [31] [32] [33] [34] [35]. The present study observed the negative effect of obesity on the ovarian response in IVF/ICSI cycles looking at the rate of cancellation of the cycle due to the insufficient number of follicles available.

In conclusion, the present study evaluated the obesity in relation to the cancellation rate in IVF/ICSI cycles. Overweight affects ovulation [36]-[43], if we consider the cause of cancellation being insufficient number of follicles reflects the poor response [44] [45]. The fertilization and pregnancy rate were not affected once oocytes retrieved [46] [47] [48]. The reduction of weight is an important part of infertility treatment in obese women with regards to the ovarian response and abortion rate.

\section{Conflict of Interest}

No conflict of interest was declared by the authors.

\section{Financial Disclosure}

The authors declared that this study received no financial support.

\section{First Author Details}

Jeddah Fertility Center, Obstetrics and Gynecology Department, Dr. Erfan \& Bagedo General Hospital, Jeddah, Kingdom of Saudi Arabia hhashimh@aol.com.

\section{References}

[1] World Health Organization. 10 Facts on Obesity. http://www.who.int/features/factfiles/obesity/en/

[2] World Health Organization. Obesity and Overweight. http://www.who.int/mediacentre/factsheets/fs311/en/

[3] Kalra, S. and Unnikrishnan, A. (2012) Obesity in India: The Weight of the Nation. Journal of Medical Nutrition and Nutraceuticals, 1, 37-41. https://doi.org/10.4103/2278-019X.94634

[4] Kumbak, B., Oral, E. and Bukulmez, O. (2012) Female Obesity and Assisted Reproductive Technologies. Seminars in Reproductive Medicine, 30, 507-516. https://doi.org/10.1055/s-0032-1328879

[5] Pfeifer, S., Fossum, G., Pisarska, M., Widra, E., Sandlow, J., Rosen, M., et al. (2015) Obesity and Reproduction: A Committee Opinion. Fertility and Sterility, 104, 1116-1126. https://doi.org/10.1016/j.fertnstert.2015.08.018

[6] Clark, A.M., Ledger, W., Galletly, C., Tomlinson, L., Blaney, F., Wang, X., et al. 
(1995) Weight Loss Results in Significant Improvement in Pregnancy and Ovulation Rates in Anovulatory Obese Women. Human Reproduction, 10, 2705-2712. https://doi.org/10.1093/oxfordjournals.humrep.a135772

[7] Clark, A.M., Thornley, B., Tomlinson, L., Galletley, C. and Norman, R.J. (1998) Weight Loss in Obese Infertile Women Results in Improvement in Reproductive Outcome for All Forms of Fertility Treatment. Human Reproduction, 13, 1502-1505. https://doi.org/10.1093/humrep/13.6.1502

[8] Bellver, J., Pellicer, A., García-Velasco, J.A., Ballesteros, A., Remohí, J. and Meseguer, M. (2013) Obesity Reduces Uterine Receptivity: Clinical Experience from 9587 First Cycles of Ovum Donation with Normal Weight Donors. Fertility and Sterility, 100, 1050-1058. https://doi.org/10.1016/j.fertnstert.2013.06.001

[9] Veleva, Z., Tiitinen, A., Vilska, S., Hydén-Granskog, C., Tomás, C., Martikainen, H., et al. (2008) High and Low BMI Increase the Risk of Miscarriage after IVF/ICSI and FET. Human Reproduction, 23, 878-884. https://doi.org/10.1093/humrep/den017

[10] Balsells, M., García-Patterson, A. and Corcoy, R. (2016) Systematic Review and Meta-Analysis on the Association of Prepregnancy Underweight and Miscarriage. European Journal of Obstetrics \& Gynecology and Reproductive Biology, 207, 73-79. https://doi.org/10.1016/j.ejogrb.2016.10.012

[11] Maheshwari, A., Scotland, G., Bell, J., McTavish, A., Hamilton, M. and Bhattacharya, S. (2009) The Direct Health Services Costs of Providing Assisted Reproduction Services in Overweight or Obese Women: A Retrospective Cross-Sectional Analysis. Human Reproduction, 24, 633-639. https://doi.org/10.1093/humrep/den424

[12] Pandey, S., Pandey, S., Maheshwari, A. and Bhattacharya, S. (2010) The Impact of Female Obesity on the Outcome of Fertility Treatment. Journal of Human Reproductive Science, 3, 62-67. https://doi.org/10.4103/0974-1208.69332

[13] Jungheim, E.S., Schon, S.B., Schulte, M.B., DeUgarte, D.A., Fowler, S.A. and Tuuli, M.G. (2013) IVF Outcomes in Obese Donor Oocyte Recipients: A Systematic Review and Meta-Analysis. Human Reproduction, 28, 2720-2727. https://doi.org/10.1093/humrep/det292

[14] Veeck, L.L. (2003) Does the Developmental Stage at Freeze Impact on Clinical Results Post-Thaw? Reproductive BioMedicine Online, 6, 367-374. https://doi.org/10.1016/S1472-6483(10)61859-7

[15] Anderson, A.R., Wilkinson, S.S., Price, S. and Crain, J.L. (2005) Reduction of High Order Multiples in Frozen Embryo Transfers. Reproductive BioMedicine Online, 10, 402-405. https://doi.org/10.1016/S1472-6483(10)61803-2

[16] Elenis, E., Svanberg, A.S., Lampic, C., Skalkidou, A., Åkerud, H. and Sydsjö, G. (2015) Adverse obstetric Outcomes in Pregnancies Resulting from Oocyte Donation: A Retrospective Cohort Case Study in Sweden. BMC Pregnancy Childbirth, 15, 247. https://doi.org/10.1186/s12884-015-0687-9

[17] Bellver, J., Rossal, L.P., Bosch, E., Zúñiga, A., Corona, J.T., Meléndez, F., et al. (2003) Obesity and the Risk of Spontaneous Abortion after Oocyte Donation. Fertility and Sterility, 79, 1136-1140. https://doi.org/10.1016/S0015-0282(03)00176-6

[18] Styne-Gross, A., Elkind-Hirsch, K. and Scott Jr., R.T. (2005) Obesity Does Not Impact Implantation Rates or Pregnancy Outcome in Women Attempting Conception through Oocyte Donation. Fertility and Sterility, 83, 1629-1634. https://doi.org/10.1016/j.fertnstert.2005.01.099

[19] Veleva, Z., Orava, M., Nuojua-Huttunen, S., Tapanainen, J.S. and Martikainen, H. (2013) Factors Affecting the Outcome of Frozen-Thawed Embryo Transfer. Human 
Reproduction, 28, 2425-2431. https://doi.org/10.1093/humrep/det251

[20] Wang, J., Li, R., Ouyang, N., Zheng, L., Ou, S. and Wang, W. (2015) Comparison of Clinical Outcomes of Vitrified-Thawed Embryo Transfer and Fresh Embryos Transfer. Chinese Journal of Epidemiology, 36, 176-180.

[21] Bhattacharya, S., Campbell, D.M., Liston, W.A. and Bhattacharya, S. (2007) Effect of Body Mass Index on Pregnancy Outcomes in Nulliparous Women Delivering Singleton Babies. BMC Public Health, 7, 168. https://doi.org/10.1186/1471-2458-7-168

[22] Brewer, C.J. and Balen, A.H. (2010) The Adverse Effects of Obesity on Conception and Implantation. Reproduction, 140, 347-364.

https://doi.org/10.1530/REP-09-0568

[23] Hamilton-Fairley, D., Kiddy, D., Watson, H., Paterson, C. and Franks, S. (1992) Association of Moderate Obesity with a Poor Pregnancy Outcome in Women with Polycystic Ovary Syndrome Treated with Low Dose Gonadotrophin. British Journal of Obstetrics and Gynaecology, 99, 128-131. https://doi.org/10.1111/j.1471-0528.1992.tb14470.x

[24] Waller, D.K., Mills, J.L., Simpson, J.L., Cunningham, G.C., Conley, M.R., Lassman, M.R., et al. (1994) Are Obese Women at Higher Risk for Producing Malformed Offspring? American Journal of Obstetrics \& Gynecology, 170, 541-548. https://doi.org/10.1016/S0002-9378(94)70224-1

[25] Norman, R.J., Noakes, M., Wu, R., Davies, M.J., Moran, L. and Wang, J.X. (2004) Improving Reproductive Performance in Overweight/Obese Women with Effective Weight Management. Human Reproduction Update, 10, 267-280.

https://doi.org/10.1093/humupd/dmh018

[26] Robker, R.L., Akison, L.K., Bennett, B.D., Thrupp, P.N., Chura, L.R., Russell, D.L., et al. (2009) Obese Women Exhibit Differences in Ovarian Metabolites, Hormones, and Gene Expression Compared with Moderate-Weight Women. Journal of Clinical Endocrinology \& Metabolism, 94, 1533-1540. https://doi.org/10.1210/jc.2008-2648

[27] Dokras, A., Baredziak, L., Blaine, J., Syrop, C., VanVoorhis, B.J. and Sparks, A. (2006) Obstetric Outcomes after in Vitro Fertilization in Obese and Morbidly Obese Women. Obstetrics \& Gynecology, 108, 61-69. https://doi.org/10.1097/01.AOG.0000219768.08249.b6

[28] Rittenberg, V., Seshadri, S., Sunkara, S.K., Sobaleva, S., Oteng-Ntim, E. and El-Toukhy, T. (2011) Effect of Body Mass Index on IVF Treatment Outcome: An Updated Systematic Review and Meta-Analysis. Reproductive BioMedicine Online, 23, 421-439. https://doi.org/10.1016/j.rbmo.2011.06.018

[29] Luke, B., Brown, M.B., Stern, J.E., Missmer, S.A., Fujimoto, V.Y. and Leach, R.E. (2011) Female Obesity Adversely Affects Assisted Reproductive Technology (ART) Pregnancy and Live Birth Rates. Human Reproduction, 26, 245-252. https://doi.org/10.1093/humrep/deq306

[30] Sneed, M.L., Uhler, M.L., Grotjan, H.E., Rapisarda, J.J., Lederer, K.J. and Beltsos, A.N. (2008) Body Mass Index: Impact on IVF Success Appears Age-Related. $\mathrm{Hu}$ man Reproduction, 23, 1835-1839. https://doi.org/10.1093/humrep/den188

[31] Madkour, W.A., Noah, B., Zaheer, H., Al-Bahr, A., Abdelhamid, A.M., Shaeer, M., et al. (2015) Does Sequential Embryo Transfer Improve Pregnancy Rate in Patients with Repeated Implantation Failure? A Randomized Control Study. Middle East Fertility Society Journal, 20, 255-261. https://doi.org/10.1016/j.mefs.2015.04.002

[32] Gorelick, A.N., Karvir, H.V., Elashoff, M., Parfitt, D.E., Copperman, A.B. and Beim, P.Y. (2014) Obesity Has a Greater Impact on IVF Success Rates in Patients with 
PCOS. Fertility and Sterility, 102, e93.

https://doi.org/10.1016/j.fertnstert.2014.07.315

[33] Pinborg, A., Gaarslev, C., Hougaard, C.O., Nyboe Andersen, A., Andersen, P.K., Boivin, J., et al. (2011) Influence of Female Bodyweight on IVF Outcome: A Longitudinal Multicentre Cohort Study of 487 Infertile Couples. Reproductive BioMedicine Online, 23, 490-499. https://doi.org/10.1016/j.rbmo.2011.06.010

[34] Brandes, M., Hamilton, C.J., de Bruin, J.P., Nelen, W.L. and Kremer, J.A. (2010) The Relative Contribution of IVF to the Total Ongoing Pregnancy Rate in a Subfertile Cohort. Human Reproduction, 25, 118-126.

https://doi.org/10.1093/humrep/dep341

[35] Goudas, V.T., Hammitt, D.G., Damario, M.A., Session, D.R., Singh, A.P. and Dumesic, D.A. (1998) Blood on the Embryo Transfer Catheter Is Associated with Decreased Rates of Embryo Implantation and Clinical Pregnancy with the Use of in Vitro Fertilization-Embryo Transfer. Fertility and Sterility, 70, 878-882. https://doi.org/10.1016/S0015-0282(98)00315-X

[36] Loveland, J.B., McClamrock, H.D., Malinow, A.M. and Sharara, F.I. (2001) Clinical Assisted Reproduction: Increased Body Mass Index Has a Deleterious Effect on in Vitro Fertilization Outcome. Journal of Assisted Reproduction and Genetics, 18, 382-386. https://doi.org/10.1023/A:1016622506479

[37] Matalliotakis, I., Cakmak, H., Sakkas, D., Mahutte, N., Koumantakis, G. and Arici, A. (2008) Impact of Body Mass Index on IVF and ICSI Outcome: A Retrospective Study. Reproductive BioMedicine Online, 16, 778-783. https://doi.org/10.1016/S1472-6483(10)60142-3

[38] Winter, E., Wang, J., Davies, M.J. and Norman, R. (2002) Early Pregnancy Loss Following Assisted Reproductive Technology Treatment. Human Reproduction, 17, 3220-3223. https://doi.org/10.1093/humrep/17.12.3220

[39] Esinler, I., Bozdag, G. and Yarali, H. (2008) Impact of Isolated Obesity on ICSI Outcome. Reproductive BioMedicine Online, 17, 583-587. https://doi.org/10.1016/S1472-6483(10)60249-0

[40] Wang, J.X., Davies, M. and Norman, R.J. (2000) Body Mass and Probability of Pregnancy during Assisted Reproduction Treatment: Retrospective Study. BMJ, 321, 1320-1321. https://doi.org/10.1136/bmj.321.7272.1320

[41] Kasim, K. and Roshdy, A. (2014) Body Mass Index and Pregnancy Outcome after Assisted Reproduction Treatment. International Journal of Reproductive Medicine, 2014, Article ID: 257974. https://doi.org/10.1155/2014/257974

[42] Urman, B., Yakin, K. and Balaban, B. (2005) Recurrent Implantation Failure in Assisted Reproduction: How to Counsel and Manage. A. General Considerations and Treatment Options That May Benefit the Couple. Reproductive BioMedicine Online, 11, 371-381. https://doi.org/10.1016/S1472-6483(10)60846-2

[43] Peddie, V.L., van Teijlingen, E. and Bhattacharya, S. (2005) A Qualitative Study of Women's Decision-Making at the End of IVF Treatment. Human Reproduction, 20, 1944-1951. https://doi.org/10.1093/humrep/deh857

[44] Bellver, J., Melo, M.A., Bosch, E., Serra, V., Remohi, J. and Pellicer, A. (2007) Obesity and Poor Reproductive Outcome: The Potential Role of the Endometrium. Fertility and Sterility, 88, 446-451. https://doi.org/10.1016/j.fertnstert.2006.11.162

[45] Kilic, S., Yilmaz, N., Zülfikaroglu, E., Sarikaya, E., Kose, K., Topcu, O., et al. (2010) Obesity Alters Retrieved Oocyte Count and Clinical Pregnancy Rates in High and Poor Responder Women after in Vitro Fertilization. Archives of Gynecology and Obstetrics, 282, 89-96. https://doi.org/10.1007/s00404-010-1359-7 
[46] Zhang, D., Zhu, Y., Gao, H., Zhou, B., Zhang, R., Wang, T., et al. (2010) Overweight and Obesity Negatively Affect the Outcomes of Ovarian Stimulation and in Vitro Fertilisation: A Cohort Study of 2628 Chinese Women. Gynecological Endocrinology, 26, 325-332. https://doi.org/10.3109/09513591003632100

[47] Yeung, T.W., Chai, J., Li, R.H., Lee, V.C., Ho, P.C. and Ng, E.H. (2014) The Effect of Endometrial Injury on Ongoing Pregnancy Rate in Unselected Subfertile Women Undergoing in Vitro Fertilization: A Randomized Controlled Trial. Human Reproduction, 29, 2474-2481. https://doi.org/10.1093/humrep/deu213

[48] Bellver, J., Ayllón, Y., Ferrando, M., Melo, M., Goyri, E., Pellicer, A., et al. (2010) Female Obesity Impairs in Vitro Fertilization Outcome without Affecting Embryo Quality. Fertility and Sterility, 93, 447-454.

https://doi.org/10.1016/j.fertnstert.2008.12.032 